\title{
Kurzbiografien der Autorinnen und Autoren
}

Blickle, Peter, geboren 1938, bis 2004 Ordentlicher Professor für Neuere Geschichte an der Universität Bern. Stipendiat des Historischen Kollegs 1993/1994. Zuletzt erschienen: Von der Leibeigenschaft zu den Menschenrechten. Eine Geschichte der Freiheit in Deutschland (München 22006); Die Revolution von 1525 (München ${ }^{4} 2004$ ).

Brady Jr., Thomas A., geboren 1937, Professor Emeritus für Geschichte an der Universität von Kalifornien, Berkeley. Stipendiat des Historischen Kollegs 1998/ 1999. Zuletzt erschien: German Histories in the Age of Reformations, 1400-1650 (Cambridge 2009).

Karant-Nunn, Susan C., Direktorin der Abteilung für Spätmittelalter und Reformationsstudien und Regents Professorin für Geschichte an der Universität von Arizona, Tucson. 1998-2010 Mitherausgeberin des Archivs für Reformationsgeschichte in Nordamerika, Präsidentin der Sixteenth Century Studies Conference und der Society for Reformation Research. Forschungsschwerpunkt ist die Sozialund Kulturgeschichte der Reformation im deutschsprachigen Raum. Zuletzt erschien: The Reformation of Feeling: Shaping the Religious Emotions in Early Modern Germany (Oxford University Press 2010).

Kaufmann, Thomas, geboren 1962, Professor für Kirchengeschichte an der Universität Göttingen; Vorsitzender des Vereins für Reformationsgeschichte; Erster Vizepräsident der Akademie der Wissenschaften zu Göttingen. Jüngste Veröffentlichungen: Der Anfang der Reformation. Studien zur Kontextualität der Theologie, Publizistik und Inszenierung Luthers und der reformatorischen Bewegung (Tübingen 2012); An den christlichen Adel deutscher Nation, Kommentare zu Schriften Luthers Bd. 3 (Tübingen 2014); Luthers Juden (Stuttgart 2014).

Krentz, Natalie, geboren 1980, wissenschaftliche Mitarbeiterin am Lehrstuhl für Neuere Geschichte an der Universität Erlangen-Nürnberg. 2006-2010 Doktorandin am Graduiertenkolleg „Gesellschaftliche Symbolik im Mittelalter“ an der Universität Münster. Jüngst erschien ihre Dissertation: Ritualwandel und Deutungshoheit. Die frühe Reformation in der Residenzstadt Wittenberg (1500-1533) (Tübingen 2014). 
LePpin, Volker, geboren 1966, seit 2010 Professor für Kirchengeschichte an der Evg.-Theol. Fakultät Tübingen sowie Direktor des Instituts für Spätmittelalter und Reformation, Ordentliches Mitglied der Heidelberger Akademie der Wissenschaften und korrespondierendes Mitglied der Sächsischen Akademie der Wissenschaften. Jüngste Veröffentlichungen: Martin Luther. Vom Mönch zum Feind des Papstes (Darmstadt 2013); Die Reformation (Darmstadt 2013).

Reinhard, Wolfgang, geboren 1937, bis 2002 Ordinarius für Neuere Geschichte in Freiburg. Stipendiat des Historischen Kollegs 1997/1998. 2001 Preis des Historischen Kollegs. Zuletzt erschienen: Paul V. Borghese (1605-1621). Mikropolitische Papstgeschichte (Stuttgart 2009); Die Nase der Kleopatra: Ein Spaziergang durch die Weltgeschichte. (Freiburg i. Br. 2011).

Rhein, STEFan, geboren 1958, seit 1998 Direktor der Stiftung Luthergedenkstätten in Sachsen-Anhalt. Seit 2000 Vorsitzender der kulturtouristischen Initiative „Wege zu Luther“ e.V. Zuletzt erschienen: Der Wein ist gesegnet. Martin Luther und der Wein (Wiesbaden 2012); „... das entscheidenste und inhaltsschwerste, was des Reformators Feder je geschrieben“ - Luthers Brief an Kaiser Karl V. (28. April 1521), in: Meilensteine der Reformation. Schlüsseldokumente der frühen Wirksamkeit Martin Luthers, hrsg. v. I. Dingel, H.P. Jürgens (Gütersloh 2014) 145-158.

Schilling, Heinz, geboren 1942, bis 2010 Ordentlicher Professor für Europäische Geschichte der Frühen Neuzeit an der Humboldt-Universität zu Berlin. Stipendiat des Historischen Kollegs 2004/2005. Für das vorliegende Thema einschlägige Buchpublikationen: Die neue Zeit. Vom Christenheitseuropa zum Europa der Staaten. 1250 bis 1750 (Berlin 1999); Martin Luther: Rebell in einer Zeit des Umbruchs. Eine Biographie (München ${ }^{3} 2014$ ).

Schmidt, Georg, geboren 1951, seit 1993 Professor für Geschichte der Frühen Neuzeit an der Friedrich-Schiller-Universität Jena. Stipendiat des Historischen Kollegs 2007/2008. Zuletzt erschienen: Wandel durch Vernunft. Deutsche Geschichte im 18. Jahrhundert (München 2009); Der „Leu aus Mitternacht“. Politische und religiöse Deutungen König Gustavs II. Adolf von Schweden. in: Gott in der Geschichte. Zum Ringen um das Verständnis von Heil und Unheil in der Geschichte des Christentums, hrsg. v. Mariano Delgado, Volker Leppin (Stuttgart 2013) 325349.

Seidel Menchi, Silvana, geboren 1942, bis 2010 Professorin für Neuere Geschichte an der Universität Pisa. Gastprofessur an der École des Hautes Études en Sciences Sociales in Paris (1996, 2003, 2007). Zuletzt erschien: Erasmus of Rotterdam, „Iulius exclusus“ (Leiden 2013).

Slenczka, Notger, geboren 1960, seit 2006 Professor für Systematische Theologie an der Humboldt Universität zu Berlin. Jüngst erschienen: Die neue Paulus- 
perspektive und die lutherische Theologie, in: Lutherjahrbuch 80. Jg., Organ der internationalen Lutherforschung (Göttingen 2013) 184-196; Luther's Anthropology, in: Robert Kolb u. a. (Hrsg.), The Oxford Handbook of Martin Luthers Theology (Oxford 2014) 212-232.

SlencZKa, Ruth, geboren 1967, bis 2013 wissenschaftliche Mitarbeiterin am Institut für Geschichtswissenschaften der Humboldt-Universität zu Berlin. Jüngste Veröffentlichungen: Luthers Grabplatte als ,protestantische Reliquie', in: Ursula Röper, Martin Treml (Hrsg), Heiliges Grab - Heilige Gräber. Aktualität und Nachleben von Pilgerorten (Berlin 2014) 102-111; Die Heilsgeschichte des Lebens: Altersinschriften in der nordalpinen Porträtmalerei des 15. und 16. Jahrhunderts, in: Zeitschrift für Kunstgeschichte 76 (2013) 493-540.

Tewes, GöTZ-RÜDIgER, geboren 1958, seit 1997 habilitierter Privatdozent der Mittelalterlichen Geschichte an der Kölner Universität und seit 2010 Lehrer für Geschichte und Philosophie am Gymnasium Odenthal. Zuletzt erschien: Kampf um Florenz. Die Medici im Exil (1494-1512) (Köln, Weimar, Wien 2011).

Wendebourg, Dorothea, Ordentliche Professorin für Kirchengeschichte an der Humboldt-Universität zu Berlin. Zuletzt erschienen: Reformationsjubiläum von 1921, in: ZThK 110 (2013) 316-361; „Gesegnet sei das Andenken Luthers!“ Die Juden und Martin Luther im 19. Jahrhundert, in: ZRGG 65 (2013) 235-25.

Wolgast, Eike, geboren 1936, Ordentlicher Professor für Neuere Geschichte an der Ruprecht-Karls-Universität Heidelberg (seit 2004 Emeritus). Jüngste Veröffentlichung: Die Einführung der Reformation und das Schicksal der Klöster im Reich und in Europa (Gütersloh 2014). 
